\title{
THE RISK OF SUBJECTIVE SYMPTOMS IN MOBILE PHONE USERS IN POLAND - AN EPIDEMIOLOGICAL STUDY
}

\author{
AGATA SZYJKOWSKA ${ }^{1}$, ELŻBIETA GADZICKA ${ }^{1}$, WIESŁAW SZYMCZAK ${ }^{2}$, and ALICJA BORTKIEWICZ ${ }^{1}$ \\ ${ }^{1}$ Nofer Institute of Occupational Medicine, Łódź, Poland \\ Department of Work Physiology and Ergonomics \\ ${ }^{2}$ University of Lodz, Łódź, Poland \\ Department of Psychological Research Methodology and Statistics
}

\begin{abstract}
Objectives: To assess the type and incidence of subjective symptoms related to the use of mobile phones in Polish users. Material and Methods: The study was conducted in 2005 using a questionnaire survey. Although it has been quite a long time, up to now, no such data have been published for Poland. The questionnaire consisted of 53 questions concerning sex, age, education, general health, characteristics of a mobile phone (hand-held, loud-speaking unit) as well as the habits associated with its use (frequency and duration of calls, text messages, etc.) and complaints associated with using a mobile phone. Results: As many as 1800 questionnaires were sent. The response was obtained from 587 subjects aged $32.6 \pm 11.3$ (48.9\% women, $51.1 \%$ men); the age did not differ significantly between men and women. The subjects owned a cell phone for an average of 3 years. Majority of the respondents used the phone intensively, i.e. daily (74\%) or almost daily (20\%). Headaches were reported significantly more often by the people who talked frequently and long in comparison with other users $(63.2 \%$ of the subjects, $p=0.0029)$, just like the symptoms of fatigue $(45 \%, p=0.013)$. Also, the feeling of warmth around the ear and directly to the auricle was reported significantly more frequently by the intensive mobile phone users, compared with other mobile phone users $(47.3 \%, \mathrm{p}=0.00004$ vs. $44.6 \%, \mathrm{p}=0.00063$, respectively). Most symptoms appeared during or immediately after a call and disappeared within $2 \mathrm{~h}$ after the call. Continuous headache, persisting for longer than $6 \mathrm{~h}$ since the end of a call, was reported by $26 \%$ of the subjects. Conclusions: Our results show that the mobile phone users may experience subjective symptoms, the intensity of which depends on the intensity of use of mobile phones.
\end{abstract}

Key words:

Electromagnetic fields, Feeling of warmth, Headaches, Cell phone, Subjective complaints

\section{INTRODUCTION}

Studies on biological effects of radio-frequency and microwave electromagnetic fields (EMF) have been performed since the end of World War II and the literature on the subject includes a few thousand publications. Today, interest in the results of that research has increased considerably, because this frequency range is used by mobile phone systems.
Biological effects of EMF emitted by a mobile phone have become a subject of an intense debate. A summary of the studies' results was published lately by Kesari et al. [1]. The authors conclude that the "regular and long term use of microwave devices, especially mobile phones, can have a negative impact upon biological system, especially on brain", because the EMF source is held very close to the

Received: March 25, 2013. Accepted: March 5, 2014.

Corresponding author: A. Szyjkowska, Nofer Institute of Occupational Medicine, Work Physiology and Ergonomic Department, św. Teresy 8, 91-348 Łódź, Poland (e-mail: agatas@imp.lodz.pl). 
user's head. Although exposure due to mobile phone use is below the admissible maximum values specified in the relevant standards, it is worth noting that a lot of mobile phone users report heating and sensation of warmth around the ear $[2,3]$. The reported sensation may be associated with the rise of the core temperature and/or the increase of the temperature in the region of the ear reported by some authors and due to local blood flow changes [3].

The studies carried out so far indicate that microwave-frequency EMF, including those emitted by mobile phones, cause various types of measurable biological and health effects [3]. Many biochemical and functional changes described in connection with EMF exposure may play a vital role in the pathogenesis of various diseases; for example, increased permeability of the blood-brain barrier, or changes in activation of endogenous opioids may be the underlying factors of the headaches reported by mobile phone users [4]. On the other hand, headache can be caused by many other factors so its relationship with the EMF cannot yet be considered proven.

So far, there have been few epidemiological studies on non-cancer health effects of radio- and microwave EMF. The first data on headaches caused by exposure to microand radio-wave frequency EMF appeared already 30 years ago, but the exposure to EMF at these frequencies was not then that widespread [4]. In addition to headaches, the users of mobile phones reported fatigue and general discomfort, nausea, impaired thermoregulation [5]. Results of the questionnaire on subjective complaints of the mobile phone users conducted in Sweden, Norway, England, USA, New Zealand, Egypt, Saudi Arabia and Australia have shown that headache was the most frequently observed symptom [4,6-12].

A study in Australia showed that headache, including migraine and cluster headache, appeared during or shortly after a call was ended, and often intensified during the day. In about $50 \%$ of the subjects the pain disappeared within about $1 \mathrm{~h}$ after a call, while in the remaining subjects it continued until the evening or till the next day [8]. Some authors have confirmed a significant relationship between the frequency of headache and the use of a mobile phone [7,13], while others have not confirmed such a relationship [14]. It occurred more frequently when using analog than digital phones [9].

In large, follow-up cohort studies performed in Basel (Switzerland) among mobile and cordless phone users no symptoms (headaches and somatic complaints) or tinnitus were observed [15].

In Poland, such studies have not been performed to date. The aim of our study was to assess the nature and prevalence of subjective symptoms related to the use of mobile phones.

\section{MATERIAL AND METHODS}

The main criterion for inclusion in the study was being an owner of a mobile phone. The study involved people using cell phones both, for business and private purposes.

The following assumptions were made to estimate the required straight sample size from the general population of mobile phone users:

- the true but unknown proportion $\mathrm{P}_{\mathrm{y}}$ of the studied symptoms in the general population; its estimation is approximately 0.3 ,

- the proportion estimated from the sample should not differ from the true proportion in the general population by more than e $\times \mathrm{P}_{\mathrm{y}}$; we assumed that $\mathrm{e} \times \mathrm{P}_{\mathrm{y}}$ will be not greater than 0.06 , hence $\mathrm{e}=0.2$.

As the general population is many times greater than the required sample, the following formula was used [16]:

$$
\mathrm{n} \geq \frac{9 \times\left(1-\mathrm{P}_{\mathrm{y}}\right)}{\varepsilon^{2} \mathrm{P}_{\mathrm{y}}}=\frac{9 \times(1-0.3)}{(0.2)^{2} \times 0.3}=525
$$

It was found that the sample size should not be less than 525 persons.

The study included an evaluation of: the frequency of occurrence and type of complaints, the use of mobile phones 
(phone type, call time, the frequency of using the phone, period of being a mobile phone owner) and the assessment of the intensity of the relationship between mobile phone use and the type and frequency of complaints.

The study was conducted by the use of a questionnaire. The questionnaire was designed specifically for the study. For the purpose of preparing the questions, the authors also used the questionnaires prepared in Sweden and Australia, in order to allow comparison of the results obtained in Poland with other countries. The survey consisted of 53 questions about gender, age, education, general health, the data on a mobile phone (hand-held, loudspeaking set) as well as habits associated with its use (frequency and duration of the calls, text messages, etc.) and any possible complaints associated by the users with the use of a mobile phone. After conducting a pilot study [17] and preliminary analysis of the results, the questionnaire was sent to a larger group of respondents.

We analyzed the impact of preferences on the use of different categories of phones (landline vs. mobile) on the frequency and type of the reported symptoms. For this purpose, the study group was divided into 3 subgroups: those predominantly using a mobile phone, participants using mainly landline phones, persons using a mobile phone as often as a landline phone.

To assess the relationship between subjective symptoms and duration of mobile phone calls, the group of people who were talking on a cell phone daily was divided into 4 subgroups based on the intensity and the way of mobile phone use, i.e.: people talking seldom and for a short time, people talking seldom but for a long time, people talking often, but for a short time, people talking often and for a long time. The short-long criterion was set at $3 \mathrm{~min}$ (short for $3 \mathrm{~min}$, long - over $3 \mathrm{~min}$ ) on the basis of the actual duration of calls of the respondents. The rare-often criterion was selected on the same basis and set at rare - to 5 calls a day, often - more than 5 calls a day.

\section{Statistical analysis}

The following statistical methods were applied for the analysis of the collected material: Student's t-test (for equal or unequal variances) or equivalent $\mathrm{F}$-Snedecor test for comparing the mean values of parameters in the study groups, the Chi-square test or Fisher's exact test for comparison of the frequencies in groups, single-and multiple logistic regression models to quantify the risk of certain complaints, depending on the level of exposure, taking into account confounding factors.

\section{RESULTS}

One thousand eight hundred questionnaires were distributed in 4 regions of Poland, in urban areas. Six hundred filled in questionnaires were returned, which is $33 \%$ of all distributed ones. The analysis included 587 questionnaires, because 13 of them were incomplete. The average age of the surveyed group was $33 \pm 11$ years and it was the same among women (48.9\%) and men. More than a half $(51.3 \%)$ of the people had higher (university-level) education, $46 \%$ of them had secondary education, $1.9 \%$ professional education and only $0.9 \%$ had primary education. In the surveyed group, more men (55.4\%) had higher education compared with women (46.8\%).

The subjects owned a cell phone for a period ranging from 1 year to 9 years, an average of 3 years $(3.1 \pm 1.7)$. Men owned a mobile phone for an average of $3.5 \pm 1.8$ years (range: $0.1-9$ ) and women 2.6 \pm 1.5 years (range: $0.1-8$ ). It was found that significantly more men than women had a cell phone for more than 2 years $(p=0.001)$. Almost a half of the respondents (46.5\%) used a mobile phone as often as a landline phone and $29.6 \%$ of the participants usually used a mobile phone. As much as $71 \%$ of the respondents called and sent text messages with equal frequency. Only 5.1\% used the phone solely to send/receive text messages. The majority of men used a mobile phone $(60.7 \%)$, while the majority $(62.3 \%)$ of women used 
a landline phone. Considerably more men than women (57.6\% vs. $42.4 \%$ ) used a cell phone to talk. On the other hand, women used a mobile phone to send text messages more frequently than men $(72.4 \%$ vs. $27.6 \%, p=0.01)$.

Hands-free kits were used by $22.2 \%$ of the respondents, and significantly more men $(79.2 \%)$ than women $(p=0.0005)$ were the users of those kits. Among the respondents, more than a half $(53 \%)$ carried the phone in a purse or a briefcase. A comparable proportion of the cell phone owners carried it at the belt $(23.4 \%)$ or in the pocket $(23.6 \%)$. Only 5 people reported pain in the area where they carried the phone ( 2 persons wearing their phone at the belt, 3 persons carrying it in the pocket). Men usually carried their cell phone at the belt $(47.5 \%)$ or in a jacket pocket $(41.2 \%)$, and women usually carried it in their purses (93.1\%).

Most people used the phone daily $(74.1 \%)$ or almost daily (19.7\%). The remaining persons talked on a cell phone once a week or less frequently (6.2\%). Significantly more men than women $(80.5 \%$ vs. $68.9 \%)$ used a mobile phone everyday $(p=0.001)$. There were no differences in the length of the calls. The majority of respondents (79.1\%) used a mobile phone during the daytime, $19.7 \%$ in the evening, and $0.9 \%$ at night. For most $(69.1 \%)$ of the respondents, the average number of calls per day was 5 . More than 10 calls per day were reported by $15.1 \%$ of the participants, including one person reporting as much as 70 calls. The average duration of a call in $65 \%$ of the respondents took no longer than $3 \mathrm{~min}$, while in the case of 3 subjects the average call lasted longer than $30 \mathrm{~min}$.

\section{Assessment of health conditions}

\section{and subjective symptoms}

The majority of subjects rated their health condition as good $(59 \%)$ or very good $(22.4 \%)$, while $17.8 \%$ reported it to be average and $0.9 \%$ rated their health as poor or very poor. Among all the subjects assessing their health as very good there were $63.4 \%$ men and $36.6 \%$ women. This difference was statistically significant $(\mathrm{p}=0.016$ ).
In the study group, $8.3 \%$ of the people reported a history of hypertension, and $6.1 \%$ were treated for that condition. Ischemic heart disease was reported by $1.2 \%$ of the subjects. One person had an artificial pacemaker, 10 people reported a history of meningitis. Other chronic diseases (including diabetes, cardiac disease, gastric and duodenal ulcers, allergy) were reported by $5.3 \%$ of the people.

Most people, $68.5 \%$, reported headaches, but only $4.9 \%$ of those subjects associated them with the use of a mobile phone. In the group of the persons reporting headaches, there were significantly more women than men, $57.9 \%$ vs. $42.1 \%$, respectively ( $p=0.001)$. Dizziness was reported by $18.6 \%$ of the participants, but only $3(0.5 \%)$ people associated that symptom with the use of a mobile phone. Dizziness occurred significantly more often in women $(72.5 \%)$ than in men $(27.5 \%), p=0.001$. Other disorders within the head (tinnitus, blurred vision, etc.) were reported by $12.9 \%$ of the respondents, and those symptoms were also significantly more frequent in women than men (59.2\% vs. $40.8 \%, p=0.05)$.

Difficulties with concentration were reported by $38.3 \%$ of the respondents. Problems with falling asleep were reported by $27.1 \%$ of the subjects. Sleep disorders were not correlated with the day time at which calls took place (day, evening, night). Dermal changes within the area of face and head were reported by $12.6 \%$ of the participants. Due to the possibility of amplifying electromagnetic fields from mobile phones by metal objects, the respondents were asked whether they had amalgam fillings, metal crowns or dentures and whether they wore corrective lenses or sunglasses fitted with metal holders. Amalgam fillings were reported by $50.3 \%$, and metal dental crowns by $15.5 \%$ of the subjects. Metal-rimmed glasses were worn by $44.5 \%$, but only $27.4 \%$ of the respondents were talking on a cell phone with their glasses on.

Fatigue after a call, even when the call was a pleasant one, was reported by $7.2 \%$ of the subjects, while impaired concentration was reported by $6.1 \%$ of the participants. 
Difficulty in recalling activities performed before a call was reported by $7 \%$ of the people. Most people reported feeling of heat around the ear and in the auricle $(26.7 \%$ and $28.3 \%$ of people, respectively). The individuals also reported facial skin burning (13 people), itchy skin (7 persons), changes in the skin of the face or around the ear (1 person). For majority of the respondents $(57.6 \%)$, the complaints or symptoms were ipsilateral, i.e. occurring on the same side of the head that the respondents reported typically holding their phones.

There were no significant differences between the group of people with amalgam fillings and/or metal crowns and those without such fillings or crowns. People who while talking on a cell phone usually wore metal-rimmed glasses, reported the feeling of heat around the ear significantly less frequently than the rest (18\% vs. $28.1 \%)(p=0.026)$. Other signs and symptoms were reported with similar frequency by both groups.

These groups did not differ in terms of age and time of owning a mobile phone. It was found that in the group of people using mainly a mobile phone, headaches occurred significantly more often $(\mathrm{p}=0.0015)$ than in other groups $(9.8 \%, 1.4 \%, 3.7 \%$, respectively). This group reported a feeling of warmth around the ear and in the auricle more frequently than the remaining participants $(37.6 \%$ vs. $15.7 \%$ vs. $25.7 \%, p=0.00006)$ and $(38.7 \%$ vs. $17.1 \%$ vs. $27.6 \%, p=0.00011)$ respectively. Also the feeling of fatigue after a call appeared in this group more frequently than in the other 2 groups $(10.4 \%$ vs. $3.6 \%$ vs. $7 \%$, respectively). The difference was of borderline statistical significance $(p=0.057)$. Also short-term memory problems occurred more frequently in this group (11\% vs. $5 \%$ vs. $5.5 \%$, respectively), the difference was of borderline statistical significance $(\mathrm{p}=0.061)$.

In the majority of respondents who reported symptoms associated with mobile phone use, those problems appeared already during a call or immediately after its termination. Headache in $78.5 \%$, fatigue in $83.3 \%$, difficulty in concentrating in $95.7 \%$. Only dizziness occurred in majority of the people after a call (5 min to $0.5 \mathrm{~h}$ ).

Analysis of the time that elapsed from the end of a mobile call to the disappearance of the symptoms showed that most of the symptoms disappeared within $2 \mathrm{~h}$ after the call - dizziness in $100 \%$ of the subjects, fatigue in $91.7 \%$, difficulty in concentrating in $86.6 \%$, memory disorders in $87.5 \%$, a feeling of warmth around the ear in $97.9 \%$, itching and burning of the skin of the face in $100 \%$. Only headaches persisted for longer time; over $25 \%$ of the respondents reported headache persisting longer than for $6 \mathrm{~h}$ since the end of a call. There were no significant differences between men and women in terms of the time of appearance and disappearance of the symptoms associated with a cell phone call.

\section{Analysis of subjective symptoms depending on the duration of mobile phone calls}

It was found that nearly a half $(48.6 \%)$ of those who called rarely but for a long time reported attention deficit disorder. Most of the problems associated with talking on a cell phone occurred more frequently in the intensive mobile phone users, whose calls were frequent and long. The headaches, as well as the signs of fatigue, were reported significantly more often by the people who talked often and long in comparison with the other groups of people (63.2\%, $\mathrm{p}=0.0029$ and $45 \%, \mathrm{p}=0.013$, respectively). Also feeling of heat around the ear and directly in the auricle was reported significantly more often by the intensive mobile phone users, compared with other users $(47.3 \%$, $p=0.00004$, and $44.6 \%, p=0.00063$, respectively).

When comparing the symptoms associated with mobile phone use between men and women, it was found that those groups differ only in terms of the incidence of skin changes, which were more frequent in women. Among all the respondents who experienced such changes, there were $64.4 \%$ women and $35.6 \%$ men. This difference was statistically significant $(\mathrm{p}=0.005)$. Also, burning sensation 
of the skin on and around the ear was reported significantly more frequently by women than by men, $76.9 \%$ vs. $23.1 \%, p=0.04$.

To verify if the ailments and symptoms reported in the survey were associated with the mobile phone use, we analyzed the risk of these problems, depending on the frequency of use of a mobile phone, daily call time and the period of owning a cell phone. The frequency of calls, duration of calls and the duration of owning a cell phone were taken as parameters characterizing exposure to EMF emitted by mobile phones. The study group was divided into subgroups according to the time of owning a mobile phone (the person owning a phone for shorter than 1 year, 1-2 years, more than 2 years), according to the frequency of calls per month (participants sending/receiving a call once a month or less frequently, up to several times a week, every day), according to the total duration of calls in a day (people talking daily less than $15 \mathrm{~min}, 15-30 \mathrm{~min}$, over $30 \mathrm{~min}$ ). When analysing the risk, the group in which the parameters characterizing the exposure level were the lowest was always used as a reference group.

The analysis showed that in the people who owned a mobile phone for more than 2 years, the risk of headaches associated with the mobile phone use was 2 times higher than in those owning a phone for a period shorter than 1 year. People from the group owning a mobile phone for the longest time had a significantly higher risk of difficulty in recalling the activities performed before a call $(\mathrm{OR}=7.9, \mathrm{p}=0.043)$. The risk of feeling the heat around the ear while talking on a mobile phone in that group was also 2 times higher $(\mathrm{OR}=1.9, \mathrm{p}=0.027)$.

The risk of headaches related, according to the opinion of the subjects, to the use of a mobile phone was 10 -fold higher among the people using cell phone every day, compared to those using it once a month (OR $=10.1, \mathrm{p}=0.024)$. The risk of feeling the heat around the ear while talking on a mobile phone was also twice higher in that group $(\mathrm{OR}=2.1, \mathrm{p}=0.002)$. Most of the dependences were observed between the complaints and the duration of calls during the day. Table 1 shows the risk of the individual complaints.

Table 1. Risk of the symptoms related to mobile phone use longer than for 30 min daily

\begin{tabular}{lrr}
\hline \multicolumn{1}{c}{ Subjective symptoms } & OR & \multicolumn{1}{c}{$\mathrm{p}$} \\
\hline Dizziness & 1.7 & 0.067 \\
Headaches & 18.8 & $<0.001$ \\
Concentration & 2.2 & 0.073 \\
Memory loss & 3.1 & 0.005 \\
Warmth behind ear & 3.5 & $<0.001$ \\
Warmth on ear & 3.1 & $<0.001$ \\
\hline
\end{tabular}

OR - odds ratio.

\section{DISCUSSION}

The results of our study were compared with the results of the studies from Australia [8], Scandinavian countries [9], Saudi Arabia [12,18,19] and Iran [20]. The response rates were: for the studies performed in: Australia - 80\% [8], Norway - 58\% [9], Sweden - 66\% [9], Saudi Arabia $86.6 \%$ [18], 97\% [19] and 95\% [12], Iran - 75\% [20]. The largest numbers of participants were those obtained in the Scandinavian countries: Sweden - 7803 and Norway -2828 .

In the studies performed mainly among the students in Saudi Arabia, the number of the participants was: 873 [19], 437 [12] and 286 [18]. In all those studies, men dominated - the proportions being 57.04\% [19], $55.1 \%$ [12], 73.77\% [18]. Also in the Australian, Scandinavian (Norway and Sweden) studies, the majority of respondents were male, while in our study the number of men and women was similar ( $\mathrm{N}=284$ and 298, respectively).

On the other hand, in the Iranian study, the number of female participants $(\mathrm{N}=343)$ was larger than that of the male subjects $(\mathrm{N}=175)$. Age of our study group was similar to that in the Australian and Norwegian studies (mean: $33 \pm 11.3$ years), while in Sweden, the majority of 
Table 2. Symptoms related to mobile phone use

\begin{tabular}{|c|c|c|c|c|c|c|c|c|}
\hline \multirow[b]{2}{*}{$\begin{array}{l}\text { Subjective } \\
\text { symptoms }\end{array}$} & \multicolumn{8}{|c|}{ Respondents (\%) } \\
\hline & $\begin{array}{l}\text { study group } \\
(\mathrm{N}=587)\end{array}$ & $\begin{array}{l}\text { Norway [7] } \\
(\mathrm{N}=2828)\end{array}$ & $\begin{array}{l}\text { Sweden [7] } \\
(\mathrm{N}=7803)\end{array}$ & $\begin{array}{c}\text { Iran [20] } \\
(\mathrm{N}=518)\end{array}$ & $\begin{array}{c}\text { Saudi } \\
\text { Arabia [18] } \\
(\mathrm{N}=286)\end{array}$ & $\begin{array}{c}\text { Saudi } \\
\text { Arabia [12] } \\
(\mathrm{N}=437)\end{array}$ & $\begin{array}{c}\text { Saudi } \\
\text { Arabia [19] } \\
(\mathrm{N}=873)\end{array}$ & $\begin{array}{l}\text { Egypt [11] } \\
(\mathrm{N}=300)\end{array}$ \\
\hline Headaches & 4.9 & 11.0 & 2.5 & 47.4 & 16.10 & 20.8 & - & 43.0 \\
\hline Dizziness & 0.5 & 8.1 & 1.1 & 26.8 & - & 2.5 & - & - \\
\hline Fatigue & 7.2 & 7.7 & 1.7 & 37.4 & 24.48 & 3.0 & - & 31.6 \\
\hline Concentration & 6.1 & 4.5 & 1.4 & 29.7 & 34.27 & - & - & 28.5 \\
\hline Memory loss & 7.0 & 2.8 & 0.6 & - & 40.56 & - & - & - \\
\hline \multicolumn{9}{|l|}{ Warmth } \\
\hline behind ear & 26.7 & 22.0 & 7.7 & - & 28.32 & & 34.59 & - \\
\hline on ear & 28.3 & 23.0 & 8.7 & - & & & & \\
\hline Burning skin & 2.2 & 11.0 & 3.2 & - & 16.78 & - & - & 19.2 \\
\hline Tingling/tightness & 1.2 & 5.1 & 1.7 & - & 16.78 & - & - & - \\
\hline
\end{tabular}

respondents (86\%) were aged 40-49 years. In the Arabic studies, the mean age of the participants was similar - 18-42 years (mean \pm standard deviation $(\mathrm{M} \pm \mathrm{SD})$ : 23.74 \pm 0.5$)$ and 18-46 years (M \pm SD: 25.56 \pm 0.6$)$ [12,19]. In Egypt, the studies were performed also among 300 students [11]. The term "good" was the highest rating for respondents' health condition in the Nordic countries, Australia and Arabia, while in our study $22 \%$ of the people rated their health as very good and $59 \%$ as good.
Comparison of the types of symptoms reported by the respondents of our study and the subjects from Scandinavian countries is presented in Table 2 and Figure 1. This table applies only to those symptoms, which in the opinion of the respondents, were caused by the use of a mobile phone.

Both, in Poland and in Sweden and Norway, the most common symptom associated, in the opinion of the respondents, with the use of a mobile phone, was feeling of warmth around the ear. Heat directly on the auricle was

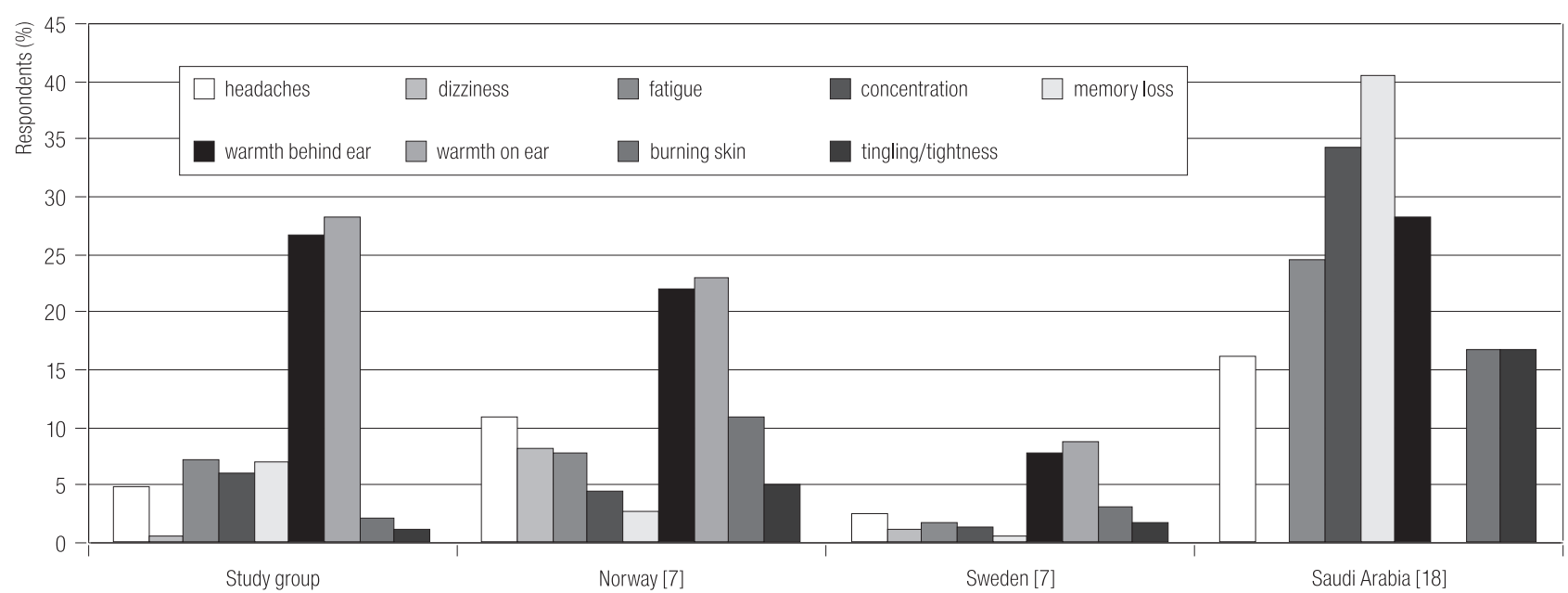

Fig. 1. Respondents reporting the symptoms related to mobile phone use in different studies 
reported by $28.3 \%$ of the people in our study, $23 \%$ of the respondents in Norway, and $8.7 \%$ in Sweden [9]. The corresponding data for the feeling of warmth around/behind the ear were 34.59\% (Saudi Arabia) [19] and 28.3\% (Saudi Arabia) [18], 26.7\% (Poland), 22\% (Norway), 7.7\% (Sweden) [9]. In Scandinavia, in addition to the feeling of heat around the ear, the respondents also reported headaches and burning sensation of the face. In Iran and Egypt, headaches were reported by almost a half of the respondents: $47.4 \%$ and $43 \%$ [11,20], respectively.

Fatigue was another symptom frequently reported by the respondents in connection with the use of a mobile phone. In Iran, headache was reported by 37.4\%, and in Egypt by $31.6 \%$ of the respondents $[11,20]$. However, in our study, in addition to feeling of heat around the ear, fatigue, especially after a call, was the second most frequently reported ailment, followed by a short-term memory loss and deterioration of concentration. In Saudi Arabia, the dominant symptoms associated with the mobile phone use were: memory impairment (40.6\%), insomnia (38.8\%), impaired concentration $(34.27 \%)$ and hearing problems (23\%) [18]. In the second study in Saudi Arabia, 34.5\% of the respondents had impaired hearing and 5.04\% reported visual disturbances [19]. In the third study headache was the most frequent symptom $(21.6 \%$ ), while only $4 \%$ of the respondents had problems with sleeping [12]. In our study problems with falling asleep were reported by $27.1 \%$ of the subjects. However, these problems were probably not related to using a mobile phone. Mohler et al. have not found any adverse effects of radiofrequency electromagnetic fields on sleep quality [21].

Dizziness and discomfort associated with face skin were significantly less common among our respondents compared with the participants in Norway, Sweden and Egypt. Comparison of our results with those of the Australian study [8] is only possible in relation to the headaches and problems occurring in a place of carrying the phone because in the Australian survey, questions concerned only those symptoms. Among the respondents, $88 \%$ of them experienced headaches occasionally, $43 \%$ - dizziness and discomfort associated with the place where the mobile phone was carried - at the belt - 7\%. Percentage of the subjects with such symptoms was significantly lower among our respondents and the respondents in the Nordic countries. Table 3 shows a comparison of the risk of complaints and symptoms associated with the use of a mobile phone in our study group and in the subjects from Scandinavian countries, calling for longer than 15 min daily.

The risk of headache and fatigue was higher in our group. However, in the studies conducted in Norway and Sweden, the authors noted a higher risk of feeling the heat around the ear and auricle (Table 3) and the burning of the face. Salama et al. (2004) [11] note that headaches were associated both with the duration of a call (above $4 \mathrm{~min}$ ) and the frequency of the calls (more than 7 calls per day). As for fatigue and pain in the region of the ear, they were associated with the duration of a call and time of being a mobile phone owner, while for face skin symptoms an association was found only with the daily frequency of the calls [11]. In the study group the majority of people who reported the symptoms associated with the mobile phone use, those symptoms appeared already during a call or immediately after its termination. Only dizziness, in $66.7 \%$ of the respondents, appeared after a conversation $(5 \mathrm{~min}-0.5 \mathrm{~h}$ ). In the Scandinavian study, fatigue and difficulty concentrating started only $30 \mathrm{~min}$ after a call [9].

Both, in our and in the Scandinavian study, the symptoms disappeared in most patients within $2 \mathrm{~h}$ after a call. Headache was the longest-lasting symptom in all the previous studies. In some cases it persisted for longer than $6 \mathrm{~h}$ after a conversation, and a few people in Australia felt it the next day. In our group, as much as $26 \%$ of the people suffered from headaches for longer than $6 \mathrm{~h}$ since the end of a call. This may be related to the increase in blood pressure during exposure to the EMF, and the stress associated with the conversation. Previous experimental studies 
Table 3. Risk of the symptoms related to mobile phone use longer than for 15 min daily

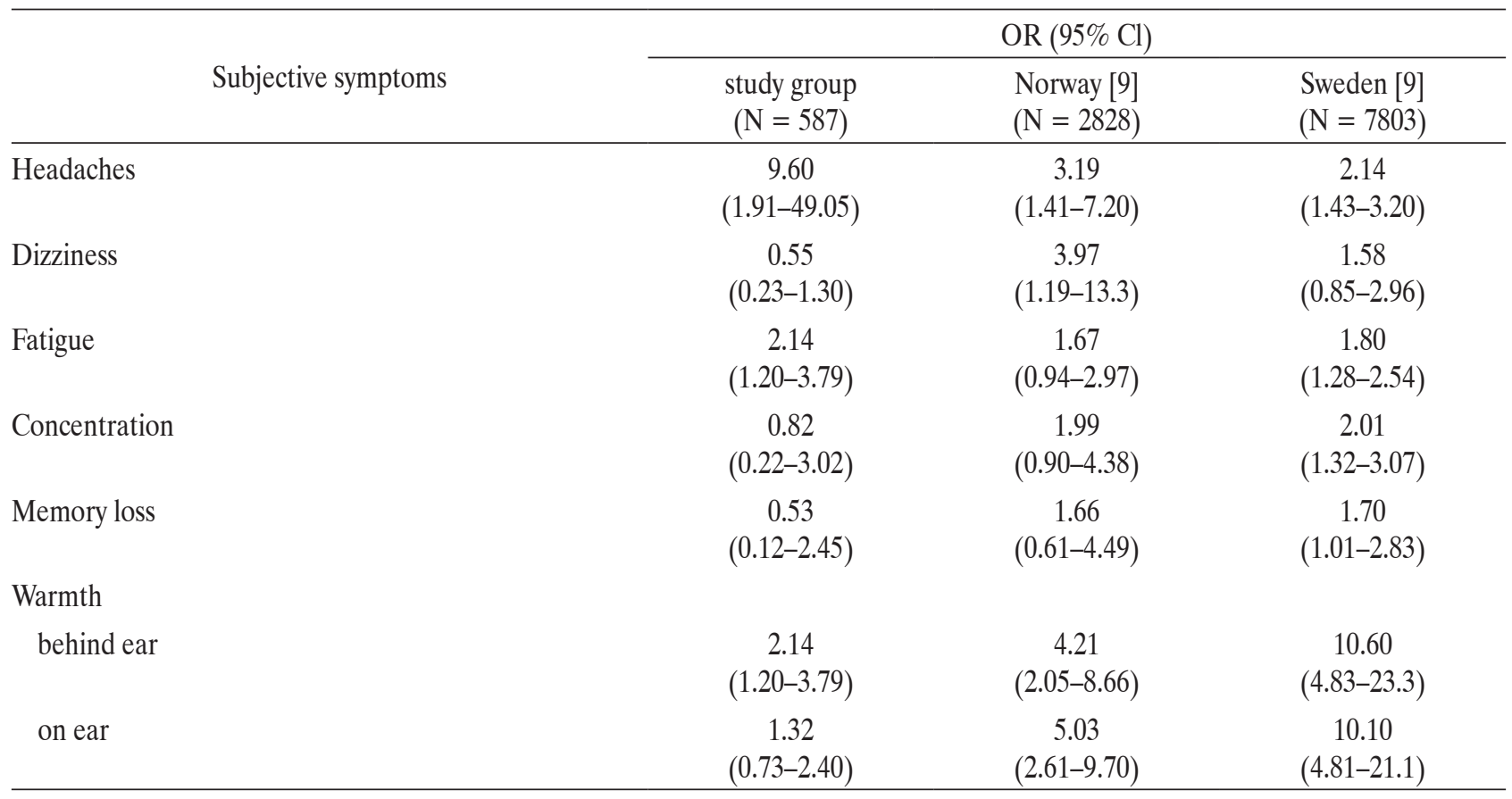

$\mathrm{OR}$ - odds ratio; $\mathrm{CI}$ - confidence intervals.

have shown that the increase in blood pressure occurs several hours after exposure to EMF emitted by a mobile phone [22,23].

When analyzing the results of our study it can be seen that the discomfort and symptoms associated with the mobile phone use occurred more frequently in those people who used the phone intensively, called often and for a long time, and in the subjects owning a mobile phone for longer than 2 years. Using a mobile phone significantly increases the risk of problems such as feeling of heat around the ear, headaches, impaired concentration as well as short-term memory, and fatigue. The risk of these problems was related to the intensity (frequency and duration of the calls) of using a mobile phone and the time of owning it. This risk was significantly increased in the people who called longer than for 30 min a day. The authors of the Egyptian studies suggest that the total time of the daily exposure be shorter than $22 \mathrm{~min} /$ day, the time of a single call be within $4 \mathrm{~min}$, and the number of calls be not greater than 7 [11].
Although the results of our research and those of the majority of other authors differ in terms of frequency of the symptoms and the time they appear, some major similarities are also evident. For example, in all populations, the main complaint was feeling of warmth felt around the ear. As to the frequency of the symptoms, our results resemble those of the Saudi Arabia studies: the most frequently reported symptoms included impaired memory as well as impaired concentration, and fatigue. Duration of the symptoms, particularly in relation to headaches, was similar to the Scandinavian studies. The reasons for the differences are difficult to explain at the current stage of research, but all the results confirm that the use of mobile phones produces the symptoms (feeling of warmth around the ear, headaches, impaired concentration as well as memory and fatigue).

It seems that the symptoms are attributable to the EMF emitted by a mobile phone rather than to the mere fact of receiving/sending a call (the risk of the symptoms was 
significantly higher in those who mostly used a mobile phone, compared to those using mainly a landline). These symptoms may adversely affect both, professional efficiency and quality of life. Currently, it is not feasible to determine the remote health effects that, advisably, should be followed-up in prospective studies. Conclusions of the review of provocation studies by Rubin et al. (2011) suggest that electromagnetic fields are not the reason of health problems among people with electromagnetic hypersensitivity [24]. However, we cannot directly compare the results of our study with those data because we performed a survey among people from general population, and not among people with idiopatic environmental intolerance atrributed to electromagnetic fields [24].

\section{CONCLUSIONS}

In our study, we could not solve the problem of the cause-effect relationship between EMF exposure and the observed symptoms. Data from the literature indicate that EMF with such frequencies as those emitted by mobile phones can affect brain function by modifying the permeability of the blood-brain barrier, as well as by changes in the active transport of $\mathrm{Na}^{+}, \mathrm{K}^{+}$and release of $\mathrm{Ca}^{++}$ions by cell membranes [25-28]. These processes affect the excitability of tissues because they, in combination with other factors, affect the mechanism of neurotransmitters release. These changes may underlie the symptoms observed in our study and associated with using mobile phones. Explanation of the subjective symptoms reported by the users of mobile phones requires further research, including both, clinical and epidemiological studies.

\section{REFERENCES}

1. Kesari KK, Siddiqui MH, Meena R, Verma HN, Kumar S. Cell phone radiation exposure on brain and associated biological systems. Indian J Exp Biol. 2013;51:187-200.
2. ICNIRP Guidelines for limiting exposure to time-varying electric, magnetic and electromagnetic fields (up to $300 \mathrm{GHz}$ ). Health Phys. 1998;74:494-522.

3. Jauchem JR. Effects of low-level radio-frequency $(3 \mathrm{kHz}$ to $300 \mathrm{GHz}$ ) energy on human cardiovascular reproductive, immune and other systems: A review of the recent literature. Int J Hyg Environ Health. 2008;211:1-29, http://dx.doi. org/10.1016/j.ijheh.2007.05.001.

4. Frey A. Headaches from cellular Telephones: Are they real and what are the implications. Environ Health Perspect. 1998;106:101-3.

5. Repacholi M. Low level exposure to radiofrequency electromagnetic fields. Health effects and research needs. Bioelectromagnetics. 1998;19:1-19, http://dx.doi. org/10.1002/(SICI)1521-186X(1998)19:1\%3C1::AIDBEM1\%3E3.0.CO;2-5.

6. Royal Society of Canada. A review of the potential health risks of radiofrequency fields from wireless telecommunication devices. Royal Society of Canada, Ottawa, Ont. 1999 [cited 2013 March 25]. Available from: http://rsc-src.ca/en/ expert-panels/rsc-reports/review-potential-health-risks-radiofrequency-fields-from-wireless.

7. Wilén J, Sandström M, Hansson Mild K. Subjective symptoms among mobile phone users - A consequence of absorption of radiofrequency fields? Bioelectromagnetics. 2003;24:152-9, http://dx.doi.org/10.1002/bem.10101.

8. Hocking B. Preliminary report: Symptoms associated with mobile phone use. Occup Med. 1998;48:357-60, http:// dx.doi.org/10.1093/occmed/48.6.357.

9. Sandström M, Wilen J, Oftedal G, Hansson Mild K. Mobile phone use and subjective symptoms. Comparison of symptoms experienced by users of analogue and digital mobile phones. Occup Med. 2001;51(1):25-35, http://dx.doi. org/10.1093/occmed/51.1.25.

10. Oftedal G, Wilén J, Sandström M, Hansson Mild K. Symptoms experienced in connection with mobile phone. Occup Med. 2000;50(4):237-45, http://dx.doi.org/10.1093/occmed/ 50.4.237. 
11. Salama OE, Abou El Naga RM. Cellular phones: are they detrimental? J Egypt Public Health Assoc. 2004;79(3-4): 197-223.

12. Al-Khlawi T, Meo SA. Association of mobile phone radiation with fatigue, headache, dizziness, tension and sleep disturbance in Saudi population. Saudi Med J. 2004;25(6):732-6.

13. Chia SE, Chia HP, Tan JS. Prevalence of headache among handheld cellular telephones users in Singapure: A community study. Environ Health Perspect. 2000;108(11):1059-62.

14. Koivisto M, Haarala C, Krauze CM, Revonsuo A, Laine M, Hamalainen H. GSM phone signal does not produce subjective symptoms. Bioelectromagnetics. 2001;22(3):212-5, http://dx.doi.org/10.1002/bem.41.

15. Frei P, Mohler E, Braun-Fahrländer C, Fröhlich J, Neubauer G, Röösli M, et al. Cohort study on the effects of everyday life radio frequency electromagnetic field exposure on non-specific symptoms and tinnitus. Environ Int. 2012;38(1): 29-36, http://dx.doi.org/10.1016/j.envint. 2011.08.002.

16. Levy PS, Lemeshow S. Sampling of populations: Methods and applications. New York: Wiley \& Sons, Inc.; 1991.

17. Szyjkowska A, Bortkiewicz A, Szymczak W, MakowiecDąbrowska T. [Subjective symptoms related to mobile phone use - A pilot study]. Pol Merk Lek. 2005;XIX(112):529-32. Polish.

18. Khan MM. Adverse effects of excessive mobile phone use. Int J Occup Med Environ Health. 2008;21(4):289-93, http:// dx.doi.org/10.2478/v10001-008-0028-6.

19. Meo SA, Al-Drees AM. Mobile phone related-hazards and subjective hearing and vision symptoms in the Saudi population. Int J Occup Med Environ Health. 2005;18(1):53-7.

20. Mortazavi SM, Ahmadi J, Shariati M. Prevalence of subjective poor health symptoms associated with exposure to electromagnetc fields among university students. Bioelectromagnetic. 2007;28(4):326-30, http://dx.doi.org/10.1002/ bem. 20305 .

21. Mohler E, Frei P, Fröhlich J, Braun-Fahrländer C, Röösli M, et al. Exposure to radiofrequency electromagnetic fields and sleep quality: A prospective cohort study. PLoS
One. 2012;7(5):e37455, http://dx.doi.org/10.1371/journal.pone. 0037455.

22. Bortkiewicz A, Jarput S, Kawabata A, Tokura H, Szymczak W, Gadzicka E. Heart rate and blood pressure during exposure to cellular phone - An experimental study. Proceedings of The 9th International Conference on Environmental Ergonomics; 2000 July 30 - August 4; Dortmund, Germany. Aachen: J.Werner \& M. Hexamer; 2000.

23. Braune S, Wracklage C, Raczek J, Lucking C. Resting blood pressure increase during exposure to a radio-frequency electromagnetic field. Lancet. 1998;351:1857-8, http://dx.doi. org/10.1016/S0140-6736(98)24025-6.

24. Rubin GJ, Hillert L, Nieto-Hernandez R, van Rongen E, Oftedal G. Do people with idiopathic environmental intolerance attributed to electromagnetic fields display physiological effects when exposed to electromagnetic fields? A systematic review of provocation studies. Bioelectromagnetics. 2011;32(8):593-609, http://dx.doi.org/10.1002/bem.20690.

25. Blackman C, Benane S, Elliot D, House D, Pollock M. Influence of electromagnetic field on the effux of calcium ions from brain tissue in vitro: A three model analysis consistent with the frequency response up to $510 \mathrm{~Hz}$. Bioelectromagnetics. 1988;9:215-27, http://dx.doi.org/10.1002/bem.2250090303.

26. Dutta S, Ghosh B, Blackman C. Radiofrequency radiation induced calcium ion effux enhancement from human and other neuroblastoma cells in culture. Bioelectromagnetics. 1989;10:197-202, http://dx.doi.org/10.1002/ bem.2250100208.

27. Fritze K, Sommer G, Schmitz B, Mies G, Hossmann K, Kiessling M, et al. Effect of global system for mobile communication (GSM) microwave exposure on blood-brain permeability in rat. Acta Neuropathol. 1997;94:465-70, http:// dx.doi.org/10.1007/s004010050734.

28. Salford L, Brun A, Sturesson K, Eberhard J, Person B. Permeability of the blood-brain barrier induced by $915 \mathrm{MHz}$ electromagnetic radiation, continous wave and modulated at 8, 16, 50, $200 \mathrm{~Hz}$. Micros Res Tech. 1994;27:535-42, http:// dx.doi.org/10.1002/jemt.1070270608.

This work is available in Open Access model and licensed under a Creative Commons Attribution-NonCommercial 3.0 Poland License - http://creativecommons.org/ licenses/by-nc/3.0/pl/deed.en. 